\title{
Strategic versus Ad-hoc Corporate Social Performance: An Analysis of CSP Maturity and Its Relationship to Corporate Financial Performance
}

\author{
Vida Skudiene ${ }^{1}$, Christine McClatchey ${ }^{2} \&$ Agne Kancleryte ${ }^{3}$ \\ ${ }^{1}$ Studies Department, ISM University of Management and Economics, Vilnius, Lithuania \\ ${ }^{2}$ MonfortCollege of Business, University of Northern Colorado, Greeley, Colorado, USA \\ ${ }^{3}$ Studies Department, ISM University of Management and Economics, Vilnius, Lithuania \\ Correspondence: Christine McClatchey, Monfort College of Business, University of Northern Colorado, Greeley, \\ Colorado, USA. Tel: 1-970-351-1248. E-mail:christine.mcclatchey@unco.edu
}

Received: June 27, 2012 Accepted: July 12, 2012 Online Published: October 9, 2012

doi:10.5539/jms.v3n1p16 URL: http://dx.doi.org/10.5539/jms.v3n1p16

\begin{abstract}
This paper extends empirical research that examines the Corporate Social Performance (CSP)-Corporate Financial Performance (CFP) relationship. Previous studies display mixed findings with no unified evidence regarding the CSP-CFP relationship's direction or impact. We introduce the concepts of strategic CSP and ad-hoc CSP, which we collectively term "CSP maturity." Using panel data on 86 large European banks and insurance companies, we investigate whether there is a relationship between a company's financial performance (CFP) and CSP maturity and, if a relationship is present, its direction and causality. Correlation analysis suggests CSP maturity and CFP are negatively related to one another; independent sample t-tests show statistically significant different means of ROA and ROS for companies engaged in strategic and ad-hoc CSP. Ad-hoc companies were on average associated with better ROA and ROS. No significant difference was present for ROE. In contrast, regression analysis did not show a relationship between CSP maturity and CFP, suggesting CSP maturity does not have an impact on CFP nor can CFP be used to explain CSP maturity. The results of this study may be limited in their generalizations because the data includes 2007-2008; a period of time the global economy experienced a major recession.
\end{abstract}

Keywords: corporate social responsibility, Europe, insurance, banking, financial performance

\section{Introduction}

In 2007 Danone donated \$18.9 million Euros (an increase of \$2.2 million Euros in 2006) to children and sports associations, research institutes, hospitals and charity organizations (Note 1). In addition to the obvious benefits to the receiving associations, and possibly a more positive societal perception of the company, an important question is whether such actions have any real effect on the donor's overall financial performance and if so, what are the underlying mechanisms that contribute to this relationship.

One of the first attempts to analyze the link between CSP and CFP was Bragdon and Marlin (1972). By 2007 there were more than 160 empirical articles and 13 meta-analyses (Margolis, Elfenbein, \& Walsh, 2007). These studies examine the strength, direction and causality of the CSP-CFP relationship across various industries using differing methodologies, levels of control, and definitions/measures of social and financial performance.

Despite these efforts, it seems there is little agreement as to: (1) whether CSP and CFP are related, (2) the direction of the relationship and, (3) the definition or measurement of both variables. Some blame the diversity of findings on differences in setting accurate operational definitions (Wu, 2006; Margolis et al., 2007); others on the scope of activities considered CSP. For example, some researchers consider engagement in a single field, like donations or environmental actions, as being CSP-engaged, while others require the firm participate in a wide range of complex activities. Of course, these differences raise questions of data reliability and comparability across studies. Similar troubles plague research on a closely related topic, corporate social responsibility (CSR), as evidenced by an entire issue devoted to that field by the Journal of Management Studies in 2006. 
From an applied perspective, companies differ in how systematically they approach CSP. Some are committed and continuously involved in CSP, while others are involved on an unsystematic basis. We introduce a company's approach and systematization of CSP as another facet of the CSP operational definition, which we call "CSP maturity." This term encapsulates the quality by which a company is involved in CSP. On one extreme is "ad-hoc CSP," which is represented by companies that are not involved in CSP at all, or are involved on a non-systematic basis. The other extreme is represented by companies that consider CSP a systematic activity and are involved on a continuous and deliberate basis. We utilize the term "strategic CSP" to capture this approach. Of course, an individual firm may be placed somewhere between the two extremes. We caution that these terms have been used in prior research, but to describe firm actions that are defined very differently from ours (Husted \& Salazar, 2006)

To analyze the CSP maturity-CFP relationship, we perform correlation analyses, independent sample t-tests and weighted least squares regression analyses. We use return on assets (ROA), return on equity (ROE) and return on sales (ROS) ratios for CFP operationalization. Three-years of panel data are examined for a sample of 86 large European banks and insurance companies. Correlation analysis, used to test the relationship's direction, shows a negative relationship between CSP maturity and CFP. T-test mean comparisons show greater ROA and ROS for companies involved in CSP on an ad-hoc basis, compared to companies that conduct CSP on strategic basis. Weighted least squares regression, which includes several control variables, is constructed to test the direction of causality between CSP maturity and CFP.

We obtain a uniform set of contextual circumstances by selecting our sample from a comparatively homogeneous industry (banks and insurance companies). These firms exhibit: (1) limited environmental, pollution, and employee/product concerns; (2) comparable stakeholder configurations; and (3) similar R\&D expenditures. Compared to manufacturing firms, banks and insurance companies may undertake and engage in a very different set of social issues, which could affect financial performance in its own distinctive manner. Griffin \& Mahon (1997) report that $78 \%$ of studies in their review used samples that included companies from multiple industries. The specific characteristics of an industry may make the nature of CSP measurement unique, based on different internal characteristics and demands. Rowley \& Berman (2000) also suggest CSP research should be narrowly defined in operation to a specific industry or setting, noting a universal measure may not be desirable or applicable.

Corporate social responsibility is an increasingly pervasive phenomenon within the European and North American economic and political landscapes. Doh \& Guay (2006) find significant differences in the institutional environments of Europe and the United States and how they affect expectations about corporation's responsibilities to society. Much of the empirical research has been conducted on U.S. companies; hence our study provides another unique perspective in that it focuses specifically on European firms and may provide insights into cultural biases not previously found.

\section{Literature Review: Defining CSP/CFP}

\subsection{Defining CSP}

The operational definition of CSP has evolved over the last few decades; as a result previous CSP-CFP studies vary significantly in what they measure. Dahlsrud (2006) notes the most frequently used CSP definition was provided by the Commission of the European Communities in 2001:

"CSP is a concept whereby companies integrate social and environmental concerns in their business operations and in their interaction with their stakeholders on a voluntary basis."

The difficulty in capturing a universally accepted CSP definition suggests is a multifaceted concept. It seems that in order to fully understand the concept, a breakdown into several categories is warranted that would simplify the term and bring more flexibility to CSP-CFP research. Two areas, measurement methods and scope, drive recent discussions.

\subsubsection{CSP Measurement Methods}

Measurement methods can differ by: (1) how the information is collected; (2) the initiation point (who initiated the measurement - e.g. the company itself, the researcher or some other third party); (3) data source (e.g. the company itself or external observers); and (4) by data type (e.g. factual data or opinion).

Orlitzky, Schmidt, \& Rynes (2003) identify four CSP measurement tools: CSP disclosures, reputation ratings, social audits and observable outcomes, and managerial CSP principles and values. Margolis et al. (2007) summarized measurement tools according to self-reports about social performance, observers' perception, and third-party audits and screened mutual funds. 
Third-party audits, as defined by Margolis et al. (2007), are "the systematic assessment of data by investigators who evaluate a company along a set of criteria." The popularity of mutual funds and third-party audits may be related to the fact that these methods consider not only a single activity but a whole system of activities. The most commonly used third-party audits are KLD, FTSE4good and Dow-Jones sustainability indexes. Reporting initiatives, posting particular requirements for their participants and evaluating them based on those requirements, can be also included into this category, as participation in these initiatives proves a company is being socially responsible to some degree. The most popular reporting initiatives are Global Reporting Initiative (GRI) and UN Global Compact. Figure 1 summarizes categorization of CSP measurement methods as defined by Margolis et al. (2007).

\begin{tabular}{|c|c|}
\hline \multicolumn{2}{|c|}{ Researcher Initiated } \\
\hline $\begin{array}{l}\text { Company } \\
\text { reported figures } \\
\text { and opinions }\end{array}$ & $\begin{array}{l}\text { External observers } \\
\text { (e.g. business } \\
\text { community's } \\
\text { reported opinion) }\end{array}$ \\
\hline $\begin{array}{l}\text { (Rettab, et. al., } \\
\text { 2008) }\end{array}$ & $\begin{array}{l}\text { (Alexander \& } \\
\text { Buchholz, 1978) }\end{array}$ \\
\hline
\end{tabular}

\begin{tabular}{|l|}
\hline Company Initiated \\
\hline Company reported \\
figures and opinions \\
(annual reports and other \\
CSP disclosures) \\
(Griffin \& Mahon, 1997)
\end{tabular}

\begin{tabular}{|c|c|}
\hline \multicolumn{2}{|c|}{ Third Party Initiated } \\
\hline $\begin{array}{l}\text { Third-party } \\
\text { audits and } \\
\text { mutual fund } \\
\text { screens }\end{array}$ & $\begin{array}{l}\text { Third party reported } \\
\text { opinions (TOP } \\
\text { company ratings in } \\
\text { magazines) }\end{array}$ \\
\hline $\begin{array}{l}\text { (Callan \& } \\
\text { Thomas, 2009) }\end{array}$ & $\begin{array}{l}\text { (Griffin \& Mahon, } \\
\text { 1997) }\end{array}$ \\
\hline
\end{tabular}

Figure 1. CSP measurement method classification by Margolis et al. (2007)

\subsubsection{CSP Scope}

The second issue related to defining CSP is the scope of a corporation's social activities. Studies vary widely in the range activities examined. For example, some utilize a single activity such as donations (Brammer \& Millington, 2008) or environmentally-targeted initiatives (Hart \& Ahuja, 1996); others use third-party audits and screened mutual funds (Callan \& Thomas, 2009; Lopez, Garcia, \& Rodriguez, 2007), covering more than one aspect of CSP.

Margolis et al. (2007) categorized the scope of 167 studies based on CSP manifestations, identifying five dimensions: revealed misdeeds, transparency, corporate policies, the environment, and donations. While much attention was given to transparency, revealed misdeeds and corporate policies in the 1970s and 1980s, the popularity of these diminished in subsequent years, with the focus of recent studies shifting primarily to the environment, with charitable donations a near second. Margolis et al. (2007) also identified four ways researchers attempted to appraise a company's CSP. While self-reporting and observer perceptions played a prominent role, screened mutual funds and third-party audits have dominated from 1990-2007.

A more generalized approach to CSP scope classification has been suggested by Dahlsrud (2006) who notes most definitions refer to one of five dimensions: social, economic, environmental, voluntariness, and stakeholders. The voluntariness dimension represents CSP activities beyond legal obligations and represents the quality with which the company is involved in CSP. Interaction with stakeholders defines the involved parties (Figure 2).

\begin{tabular}{|l|}
\hline CSP Scope \\
\hline Social \\
Organization's \\
impacts on customers, \\
employees and \\
society in general. \\
\hline
\end{tabular}

\begin{tabular}{|l|} 
Economic \\
Organization's impact on \\
it's stakeholder's \\
economic conditions and \\
on the economic system.
\end{tabular}

\begin{tabular}{|l|l|l|}
$\begin{array}{l}\text { Environment } \\
\text { Organization's } \\
\text { impacts on living } \\
\text { and non-living } \\
\text { natural systems. }\end{array}$ & & $\begin{array}{l}\text { Voluntariness } \\
\text { Beyond legal } \\
\text { involvement. }\end{array}$ \\
\end{tabular}

\begin{tabular}{|l|} 
Stakeholders \\
Focus on \\
stakeholders.
\end{tabular}

Figure 2. CSP scope according to Dahlsrud (2006)

As Dahlsrud (2006) formulates, CSP scope is always context specific and though all five dimensions are mentioned in most CSP definitions, the areas a company is involved in will depend on its own needs, market and capacities. This is very much in line with how CSP scope is defined by third-party audit methodologies. Though 
they have formal criteria covering environmental, social and in some cases economic impacts, they are still constructed in a flexible way, so that industry and company specifics may be considered.

To conclude, there is no predefined set of CSP activities a company must be involved in to be considered socially responsible. Most often CSP initiatives and contributions are contextual, consider stakeholders needs on a voluntary basis, and are related to environmental, social and economic issues.

\subsection{Defining CFP}

Similar to CSP, the definition of CFP also varies in scope and measurement across previous studies. Margolis et al. (2007) note the majority of studies utilize data from COMPUSTAT or AMADEUS as well as information provided by stock exchanges. Some refer to self-reported data, which is gathered by the help of questionnaires. Popular magazine ratings have also been used as CFP indicators.

An extensive analysis of CFP indicators was performed by Griffin \& Mahon (1997). They analyzed 51 researches and grouped CFP measures into six categories, presented in Figure 3. The authors identified more than 80 CFP indicators; however many of the indicators were used only once and research was rarely repeated by other scholars.

\begin{tabular}{|ll|}
\hline Profitability & ROE, ROS, ROI, Net Income, Earnings per share, Profit margin, Sales/Equity, Equity \\
\hline Asset Utilization & ROA, Asset turnover, Asset age \\
\hline Growth & Total assets, ROA, ROE, ROS, ROI, Asset turnover, Earnings per share growth \\
\hline Liquidity & Acid test, Change in cash flow, Current ratio, Current assets/total assets, Cash flow per share, \\
\hline $\begin{array}{l}\text { Risk/market } \\
\text { measures }\end{array}$ & $\begin{array}{l}\text { Excess market valuation/abnormal returns, Beta, Alpha, Net losses, Share price, P/E, Returns } \\
\text { on portfolio, Market share, Dividends per share, Percent change in dividends }\end{array}$ \\
\hline Other & $\begin{array}{l}\text { Ownership type, Perceptual measures, Advertising, Executive/employee compensation, } \\
\text { Diversification, Leverage }\end{array}$ \\
\hline
\end{tabular}

Figure 3. CFP measures summary by Griffin and Mahon (1997)

Orlitzky et al. (2003) summarizes three broad subdivisions of CFP measures: accounting, market and perceptual measures. While accounting measures capture past performance, market measures evaluate future performance, but are considered noisier since they are affected by external factors. Alternatively, accounting data can also be influenced by company management especially in those cases when accounting results influence management compensation. This phenomenon can be linked with endogeneity problems and has been analyzed by Garcia-Castro, Arino, \& Canela (2009). Perceptual measures involve subjective judgment based on questionnaires related to perceptions of ROA, ROE and financial position, relative to other companies. A separate group of studies uses fund returns, bond returns and stock returns as CFP indicators (Mill, 2006). These studies are designed to test if screened mutual funds perform better when compared to the S\&P 500 or Dow Jones indexes.

\section{Literature Review: CSP - CFP Relationship and Causality}

Prior literature on the CSP-CFP link escalates a few main aspects. Specifically, much attention has been focused on: (a) the relationship direction - positive or negative; (b) the relationship causation, or which concept is the determinant; and (c) time lagging effects.

\subsection{The Relationship-Positive or Negative}

The CSP-CFP relationship has been hypothesized as both positive and negative. A growing majority of studies support the notion of a positive CSP-CFP relationship (Callan \& Thomas, 2009; Hillman \& Keim, 2001; Peters \& Mullen, 2009; Rettab, Brik, \& Mellahi, 2008; Simpson \& Kohers, 2002; Waddock \& Graves, 1997). A positive relationship is explained by stakeholder theory, developed by Freeman (1984), which states the satisfaction of stakeholder groups can affect a company's financial performance. In other words, a company may perform better financially by bringing value not only to its shareholders, but also to various stakeholders groups such as employees, clients, suppliers and society in general. From this perspective, is logical to assume CSP maturity will have positive relationship with CFP.

Other scholars believe CSP and CFP are negatively related. This notion, supported by the traditionalist view (Friedman, 1970), has received less support as of recent. As explained by Friedman (1970), a company engaged 
in CSP deviates from its initial objective, which is to maximize profit, and incurs costs that otherwise could be avoided. According to this line of thinking, CSP leads to limited benefits for the company with significant additional costs thus it will not lead to improved CFP. Studies which find a negative relationship include Laan, Ees, \& Witteloostuijn (2007), Lopez et al. (2007), Makni, Francoeur, \& Bellavance (2008) and Garcia-Castro et al. (2009).

\subsection{Causality}

Various models for the CSP-CFP relationship framework have been proposed. Brammer and Millington (2008) suggest a non-linear relationship, but only analyze the donations aspect as a CSP manifestation. Callan and Thomas (2009) use a linear regression model, arguing CFP in time period $t_{1}$ depend on a CSP index in $t_{0}$, measuring a company's social performance across 13 indicators. Peters \& Mullen (2009) build a six-year longitudinal study with regard to ROA. All of these models raise important questions which should be addressed when building a CSP-CFP relationship model, one of which is causality.

The notion that CFP is the dependent variable and can be explained by CSP is supported by "good management" theory. This theory implies good managerial practices are accompanied by attention to social performance domains, because they involve relationship management with all stakeholders. As an example, good relationships with employees can result in better productivity, reduced court suits, and subsequently reduced expenses. Better relationships with community may bring easier regulation or tax exemptions from local authorities. Consumers' opinion about the quality of goods and services, and the firm's friendliness to the environment can bring positive effects to the company's brand. This theory is supported by Callan \& Thomas (2009) and Peters \& Mullen (2009).

Other studies have found the opposite causation (Waddock \& Graves, 1997; Uwuigbe \& Egbide, 2012). This approach is supported by the "slack resource theory" which argues better financial performance leads to slack financial and other resources that firm's may use to more fully engage in CSP activities.

\subsection{Time Lagging}

Time lagging is an important concept when evaluating the CSP-CFP link. Once again, empirical evidence is mixed. Griffin \& Mahon (1997) suggest studies should take into consideration a longer time period. It is reasonable to expect that, just like any other capital investment, CSP involvement will take time to provide a return. Margolis et al. (2007) also support further investigation of time lagging. Their analysis showed that previous studies tend to address the issue of the sequence of CSP and CFP; however the lagging aspect fails to attract sufficient attention. Callan and Thomas (2009) addressed this issue by building a regression models using a one-year lag. Peters \& Mullen (2009) investigated the CSP and CFP link in a six-year study and found the effect of CSP on CFP tends to strengthen during later years. The time lagging aspect should be also valid in the CSP maturity relationship with CFP.

\section{Methodology}

We investigate the CSP maturity-CFP relationship, while clearly distinguishing between strategically managed and ad-hoc CSP to determine:

- if the relationship between CSP maturity (strategic or ad-hoc) and CFP is positive or negative;

- which is the dependent variable in the relationship;

- if companies involved in strategic CSP have better or worse financial results compared to companies involved in ad-hoc CSP.

\subsection{Sample}

Financial data is retrieved from the One Source database. CSP data is collected by the authors, using information on company web-sites, GRI, UN Global compact, FTSE4good index and Dow-Jones sustainability index pages. The sample includes European bank and insurance firms listed in the Financial Times Top 500 in 2009. This group represents European-listed companies with at least $15 \%$ of outstanding shares in market circulation. The initial sample includes 28 insurance firms and 62 banks. We exclude three insurance companies and one bank due to data unavailability so the final sample consists of 86 firms. As the sample includes both cross-sectional and time series data, it is constructed as panel data. Each firm is measured in multiple time periods, so 86 companies measured 4 times (2005 - 2008) form our dataset of 344 observations. 


\subsection{Control Variables}

We address three categories of control variables: macroeconomic, industry level and firm level (see Table 1). Similar to Goddard, Molyneux \& Wilson (2004) we include the yearly shift in GDP for each firm's country to account for macroeconomic fluctuations (DeltaGDP $)_{\mathrm{j}}$ ). Country allocation is based on firm incorporation and stock market listing, alongside market perception. In addition to the annual growth rate in GDP, we include a separate dummy variable to account for the global financial economy crisis which started in 2007 and was mostly explicitly revealed in 2008. Generally the GDP annual growth rate should cover this effect; however because the crisis had a major impact, DeltaGDP ${ }_{j}$ may be not strong enough to account for the decline in financial performance. To this end, we set the variable Crisis Dummy equal to " 1 " in 2008, and "0" otherwise.

Goddard et al. (2004) recommend a market concentration index (HHI) for the industry control variable. This would be complicated in the current study because consolidated financial data is utilized, and it is difficult to identify which market should be considered. Looking at the CSP literature, industry is an important variable, since business and management specifics, business cycles, and other factors can impact a company's involvement in CSP. To this end, we utilize a dummy variable Industry set equal to " 1 " for banks and " 0 " for insurance companies. The final group of control variables is based on prior literature to reflect company specific data and includes:

- TA: Total assets

- Empl: Number of employees

- D/E: Debt-to-equity ratio

- Capex: Capital expenditures

Table 1. Summary of variables

\begin{tabular}{ll}
\hline ROA & Net operating income / average total assets \\
\hline ROE & Net operating income / equity \\
ROS & Net operating income / total revenues \\
CSP_perc & $\begin{array}{l}\text { Discrete variable indicating the percentage of years the company was involved in strategic CSP in } \\
\text { past five years }\end{array}$ \\
CSP_dummy & Dummy variable where $1=$ strategic CSP, $0=$ ad-hoc CSP \\
DeltaGDP & Annual growth rate of GDP in country j \\
Crisis Dummy & Dummy variable where $1=2008,0=$ otherwise \\
Capex & Company investments in fixed and intangible assets \\
Empl & Number of full and part-time employees \\
TA & Total assets expressed in thousands, EUR \\
D/E & Total debt divided by total equity \\
Industry & Dummy variable where $1=$ bank, $0=$ insurance company \\
\hline
\end{tabular}

\subsection{CFP Variables}

As proposed by Lankoski (2008), CSP may impact a company's financial performance by affecting either costs or revenues. We use the following profitability ratios, as they capture both aspects.

- Return on assets (ROA) is an operational performance measure used to proxy efficiency. It is calculated as net operating income divided by average total assets.

- Return on sales (ROS), also called EBIT margin, is used to measure company profitability. It is calculated as net operating income divided by total sales.

- Return on equity (ROE) is used as a proxy shareholder value or wealth. It is calculated as net operating income divided by total equity.

\subsection{CSP Variables}

We utilize company-initiated and reported figures such that the data is reliable and open for validation. In addition to the question of how to measure CSP, an important aspect suggested in recent literature is a quality perspective. This viewpoint addresses how systematically companies are involved in CSP activates and which we term "CSP maturity." Some firms are continuously involved in CSP, while others put forth effort with some interference or on an ad-hoc basis. 
CSP maturity is a wider concept than CSP scope, because it relates to the quality aspects of CSP. The difference between strategic and ad-hoc CSP lies not in the motivation, although in both cases companies probably expect some positive effect, and not necessarily from the scope of CSP or the size of its impact. The difference lies in management's maturity to its approach and the coordination of efforts which, if more concentrated and coordinated, can have a different impact on the company's financial performance. In order to differentiate strategic, from ad hoc CSP, we consider the following.

- Strategic CSP must be included into the company's business strategy.

CSP is context specific; if a firm included CSP into its strategy, it is assumed the firm has already defined the scope of CSP which would be most beneficial and applicable for its specific context.

- Strategic CSP must be supported by management procedures.

Kaplan \& Norton $(2000,2007)$ state good strategy is not enough; in many cases good strategies fail to bring advantages because management is unable to execute them properly. According to the management processes framework, strategic CSP should be supported by proper management processes. This implies strategic CSP requires having visions translated into clear objectives, goals, and targets, which are communicated throughout the organization, reviewed and adjusted in certain periods of time, and monitored in terms of results and feedback.

- Strategic CSP must be a continuous activity.

Strategy is considered a long-term plan, which means the same pattern should apply to CSP. In other words social performance, which is present on continuous basis for multiple years, may be counted as strategic; random initiatives or short-term performance are insufficient for a company to perceive positive effects.

- Strategic CSP must be publicly communicated.

Based on a KPMG study, most of the TOP 250 Global companies have a CSP strategy that is publicly reported (Note 2). If stakeholders are unaware, strategic CSP may lose part of its purpose. By distributing public reports, companies demonstrate their commitment to stakeholders and display transparency, supporting their commitment to CSP. However, some firms may abuse the power to communicate its strategy to create a positive image, without the intention to honestly address stakeholder concerns. We conclude that, without other components, external communication alone is just an exercise in public relations but without proper communication, stakeholders would not be aware of a firm's CSP activities.

- Strategic CSP must be everyone's business.

Wells (1996) and Sadler (2003) note one key aspect of strategic management is resource allocation. Companies invest money as well as time and human resources. Whether or not companies have a dedicated body to support CSP implementation, every employee must be involved in strategy delivery and, to create this commitment, communication is required. We assume strategic CSP may be supported by some corporate body, but this is not a necessary condition; as long as CSP values are communicated throughout the firm, we label the firm strategic.

Based on this review, we define a company as engaged in strategic CSP if the following criteria are satisfied. If at least one of the criteria is not met, the firm is labeled ad-hoc.

- CSP is stated as part of the firm's general business strategy;

- The company set clear objectives, measures, and targets related to CSP, and it monitors and periodically reviews the results;

- CSP involvement is communicated both publicly and throughout the organization;

- The firm is engaged in CSP on a continuous, long-term basis defined as at least three or more years of continuous involvement.

We utilize four reporting initiatives: Global Reporting Initiative (GRI), UN Global Compact Reporting Standards, inclusion in the FTSE4good, and inclusion in the Dow-Jones Sustainability Index. All of these initiatives require: (1) participants state their long-term commitment for sustainability as part of their strategy; (2) participants issue public reports with clearly defined objectives in social, economical, and environmental domains; and (3) monitoring of key performance indicators (KPI). Additionally, the reporting initiatives are not new and have been in business for more than a decade, thus they enable measurement of a firm's continued commitment.

Each firm was checked for participation in all four initiatives. Participation was measured three times (2005-2007) by referring to the prior five-year time frame. For example, the measurement in 2005 uses data for 
2001-2005. Each measurement shows the number of years the company was involved in the aforementioned initiatives. If a company was involved in several initiatives, the one which was followed the mostly systematically (without any interruptions and for the longest continuous period) is utilized. Two variables are constructed. The CSP dummy variable (CSP_dummy) indicates whether a firm is engaged in strategic CSP or ad-hoc CSP:

- Firms coded as "1" indicate strategic CSP. This group includes companies involved in any of four reporting initiatives for at least three consecutive years in the respective time frame.

- Firms coded as " 0 " indicate ad-hoc CSP. This group includes companies involved in any of four reporting initiatives for less than three consecutive years in the respective time frame.

CSP maturity percentage (CSP_perc) is calculated by dividing the number of years a firm is labeled strategic by five, producing a discrete variable containing more values and having a clear maximum of 1.0. These two variables are used as the equivalent of one another in our analyses; that is, the choice of variable is based on the strength of statistical results, as discussed in Section V.

\section{Empirical Results}

\subsection{Descriptive Statistics}

Table 2 presents descriptive statistics. The data contains 344 observations for CFP and control variables and 258 observations for CSP variables; the difference in observations is because financial data is collected for 2005-2008, while CSP data is collected for 2005-2007.

Table 2. Descriptive statistics

\begin{tabular}{llll}
\hline Variable & $\mathrm{N}$ & Mean & Standard Deviation \\
\hline ROA & 344 & 0.01 & 0.01 \\
ROE & 344 & 0.14 & 0.12 \\
ROS & 344 & 0.15 & 0.13 \\
D/E & 344 & 3.70 & 6.99 \\
Empl & 344 & 43,115 & 55,473 \\
TA & 344 & $\$ 335,398,800$ & $\$ 472,637,440$ \\
Capex & 344 & $-\$ 566,207$ & $\$ 1,198,615$ \\
DeltaGDP & 344 & 2.60 & 1.97 \\
Industry_dummy & 344 & 0.71 & 0.46 \\
CSP perc & 258 & 0.43 & 0.40 \\
CSP dummy & 258 & 0.44 & 0.50 \\
\hline
\end{tabular}

\subsection{CSP Maturity - CFP Relationship Direction}

Applying the traditionalist view to CSP maturity, one could assume CSP maturity and CFP are related negatively, because strategic CSP is a significant investment which requires additional financial and human resources, as well as time to support all the initiatives. In contrast, stakeholder theory argues a positive relationship because stakeholder groups' satisfaction can affect a company's financial performance. To test this hypothesis (H1), correlation analysis is performed. Results are provided in Table 3 (Note 3).

H1: The relationship between CSP maturity and CFP is positive.

Table 3. Spearman correlation coefficients

\begin{tabular}{lllllllll}
\hline Variable & ROA & ROE & ROS & D/E & Empl & TA & Capex & DeltaGDP $_{j}$ \\
\hline D/E & $-0.383^{* *}$ & -0.069 & -0.079 & 1.00 & & & & \\
Empl & $-0.210^{* *}$ & 0.051 & $-0.126^{*}$ & $0.283^{* *}$ & 1.00 & & & \\
TA & $-0.588^{* *}$ & $-0.186^{* *}$ & $-0.352^{* *}$ & $0.398^{* *}$ & $0.761^{* *}$ & 1.00 & & \\
Capex & $0.158^{* *}$ & -0.066 & -0.019 & $-0.261^{* *}$ & $-0.643^{* *}$ & $-0.505^{* *}$ & 1.00 & \\
DeltaGDP $_{\mathrm{j}}$ & $0.468^{* *}$ & $0.521^{* *}$ & $0.394^{* *}$ & -0.081 & -0.017 & $-0.223^{* *}$ & -0.007 & 1.00 \\
CSP_dumm_1 $^{*}$ & $-0.367^{* *}$ & $-0.318^{* *}$ & $-0.266^{* *}$ & $0.159^{*}$ & $0.216^{* *}$ & $0.383^{* *}$ & $-0.242^{* *}$ & $-0.325^{* *}$ \\
CSP_perc_1 & $-0.438^{* *}$ & $-0.358^{* *}$ & $-0.350^{* *}$ & $0.182^{* *}$ & $0.276^{* *}$ & $0.464^{* *}$ & $-0.279^{* *}$ & $-0.412^{* *}$ \\
\hline
\end{tabular}

** Significant at the 0.01 level (2-tailed)

* Significant at the 0.05 level (2-tailed) 
As seen in the shaded area of Table 3, the correlation coefficient between CFP and CSP maturity is negative and significant at the $5 \%$ level, irrespective of the measurement of CFP or CSP (-0.266 to -0.438). A negative correlation suggests $\mathrm{H} 1$ is false and should be rejected (Note 4). To understand these results more intuitively, we examine the average trend of CFP ratios during 2005-2008.

The year 2008 marked a significant event; all financial ratios exhibited a declining trend, influenced by the world economic downturn, which began late 2007, providing support for including both DeltaGDP ${ }_{j}$ and a crisis index variable in regression analyses. While ROA trends are quite similar between banks and insurance companies, the trend is different for ROS and ROE. According to the DataMonitor industry profile for European banks and insurance companies, the insurance sector experienced a decline in ROE of $3.2 \%$ in 2008 while the banking industry's ROE shrank by only $1 \%$. The differences between industries will need to be considered in further analyses.

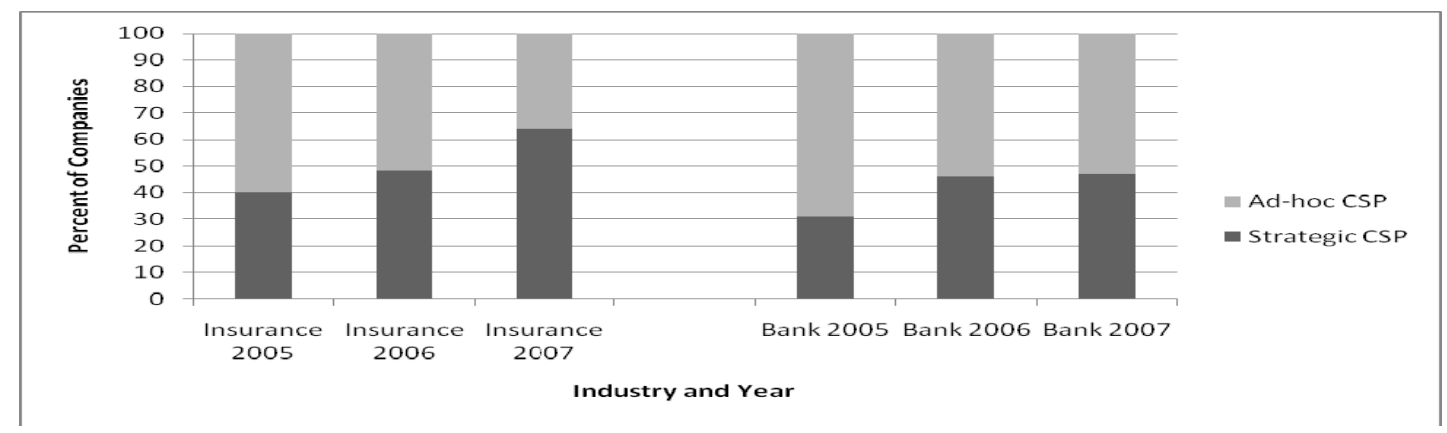

Figure 4. CSP maturity trend, 2005-2007

We also examine changes in CSP maturity during 2005-2007 (Figure 4). Interestingly, the results show an opposite trend in CSP maturity, when compared to CFP. That is, in every year companies tended to engage more in strategic CSP and abandon ad-hoc CSP activities, regardless of industry.

Our results lead to the observation that the economic crisis had a significantly negative impact on company financial results but did not have a negative effect on CSP maturity. On the contrary, correlation coefficients between the CSP dummy variable and DeltaGDP ${ }_{j}$ are mildly negative $\left(-0.412^{* *}\right)$ for both the contemporaneous CSP dummy and the CPS dummy lagged 1 year $\left(-0.325^{* *}\right)$. It seems there is reason to hypothesize the economic crisis had a positive effect on a company's involvement in strategic CSP over ad hoc CSP, similar to the results of Chih, Chih, \& Chen (2009). These scholars conclude financial firms act in more socially responsible ways to enhance their competitive advantages when market competition is intense.

To conclude, our results suggest $\mathrm{H} 1$ should be rejected. The negative relationship between CSP maturity and CFP is confirmed by a significant negative correlation coefficient for all variables. Of course, as our results are obtained with data that includes an extraordinary event (2008), they should be generalized with caution.

\subsection{CFP Mean Comparison between Strategic and Ad-hoc CSP}

Mean comparison hypotheses can also be supported by both stakeholders' theory and the traditionalist view. According to stakeholder's theory, companies that are committed to be socially responsive and do so in a systematic way should be rewarded by better financial results. Traditionalists would argue companies engaged in strategic CSP drift from their goal of profit maximization, waste resources on non-essential activities, and hence are not as effective as companies concentrated on profit maximization. To evaluate this, we test the following hypothesis:

H2: Companies engaged in strategic CSP are associated with better CFP than companies engaged in ad-hoc CSP.

A t-test for two independent samples was performed for $\mathrm{H} 2$. The samples represent companies involved either in strategic or ad-hoc CSP. Results are presented in Table 4. 
Table 4. T-test for independent samples comparison

\begin{tabular}{|c|c|c|c|c|c|}
\hline CFP ratio & $\begin{array}{lrr}\text { Levene's } & \text { Test } & \text { for } \\
\text { Equality } & & \text { of } \\
\text { Variances } & & \end{array}$ & $\begin{array}{lr}\text { P-values for } \\
\text { Equality of Means }\end{array}$ & CSP type & Mean & $\begin{array}{l}\text { Mean } \\
\text { Difference }\end{array}$ \\
\hline ROA & 0.064 & $0.057 * *$ & $\begin{array}{l}\text { Strategic CSP } \\
\text { Ad-hoc CSP }\end{array}$ & $\begin{array}{l}0.010 \\
0.014\end{array}$ & -0.003 \\
\hline ROE & 0.305 & 0.118 & $\begin{array}{l}\text { Strategic CSP } \\
\text { Ad-hoc CSP }\end{array}$ & $\begin{array}{l}0.157 \\
0.176\end{array}$ & -0.019 \\
\hline ROS & 0.064 & $0.039 *$ & $\begin{array}{l}\text { Strategic CSP } \\
\text { Ad-hoc CSP }\end{array}$ & $\begin{array}{l}0.156 \\
0.184\end{array}$ & -0.029 \\
\hline
\end{tabular}

** Significant at the $10 \%$ level

* Significant at the $5 \%$ level

We first note that mean differences in financial ratios were present in 2006 when the financial crisis was still a future event, and that the decline in financial performance was present in both groups and for all financial ratios during 2007-2008. Apparently the CSP maturity effect is too weak to prevent overall financial performance from declining during a world-wide economic downturn.

Turning to our results, we find differences in financial performance between companies involved in strategic and ad-hoc CSP are present and statistically significant for ROA and ROS, but not ROE. Companies engaging in ad-hoc CSP were, on average, associated with better financial results, leading us to reject $\mathrm{H} 2$, consistent with the traditionalist view. It is worth considering why the results may differ between ratios. According to the DuPont pyramid, ROE, ROA and ROS represent different hierarchical levels. ROS can be used to express ROA, while ROA can be used to express ROE. Operating expenses influence ROS, which then contributes to ROA, but because ROE is a third level in the pyramid, the effect may be too weak.

\subsection{CFP is Determined by CSP Maturity}

We next examine the influence of CSP maturity on CFP using weighted least squares regression analysis for each dependent variable (ROA, ROE, ROS) (Note 5). Our first model (H3) is built around the hypothesis that CFP is the dependent variable (Note 6). Looking from the CSP maturity perspective, "good management" theory argues companies will be involved in strategic CSP when they expect a payoff in terms of reduced costs or increased income.

\section{H3: CSP maturity is a determinant of CFP}

In this model, CFP (measured by one of three financial ratios) is explained by CSP maturity and other control variables. CSP maturity is measured as the percentage of years of strategic involvement in CSP in the prior 5 -year time frame. CSP perc, industry, crisis, debt/equity, employee number, total assets, capital expenditure and DeltaGDP ${ }_{j}$ are initially included as control variables. All control variables except DeltaGDP ${ }_{j}$ are lagged one year (DeltaGDP ${ }_{\mathrm{j}}$ is not lagged because it is included to account for economic shifts).

The models are first constructed with all control variables. AIC, AICC, BIC and log likelihood are used in subsequent iterations to identify which model best suits the data. Models are improved by omitting one variable at each step (see Appendices 1-3). Variables having the highest p-values are removed first. Results from the final models are presented in Table 5 .

Table 5. Weighted least squares estimated models with CFP as the dependent variable

\begin{tabular}{llll}
\hline & ROS & ROA & ROE \\
\hline const & $0.1242^{* *}$ & $0.00819^{* *}$ & $0.1728^{* *}$ \\
D/E_1 & $-0.001869^{* *}$ & $-0.0001221^{* *}$ & \\
Emp_1 & $4.957 \mathrm{e}-07^{* *}$ & $3.551 \mathrm{e}-08^{* *}$ & $4.269 \mathrm{e}-07^{* *}$ \\
DeltaGDP & & $0.001584^{* *}$ & \\
CSP_perc_1 & & $-0.001753^{* *}$ & $-0.03664^{* *}$ \\
TA_1 & $-1.355 \mathrm{e}-010^{* *}$ & $-8.531 \mathrm{e}-012^{* *}$ & $-9.103 \mathrm{e}-011^{* *}$ \\
Capex_1 & & & \\
Industry & $0.1015^{* *}$ & & $0.01906^{* *}$ \\
Crisis & $-0.07776^{* *}$ & $-0.00128^{* *}$ & $-0.08201^{* *}$ \\
\hline
\end{tabular}




\begin{tabular}{clll}
\hline $\mathrm{n}$ & 258 & 258 & 258 \\
Adj. $\mathrm{R}^{2}$ & 0.7299 & 0.7249 & 0.5602 \\
$\operatorname{lnL}$ & -356.7 & -348.1 & -352.9 \\
AIC & 725.4 & 710.0 & 717.7 \\
BIC & 746.7 & 735.0 & 726.3 \\
HQC & 734.0 & 720.0 & 739.0 \\
\hline * Significant at the 10\% level & & & \\
** Significant at the 5\% level & & &
\end{tabular}

As seen in Table 5, not all variables initially proposed are included in final regressions. Capital expenditures do not exhibit a significant impact on the model, regardless of how the dependent variable is defined. Industry is significant in the ROS and ROE models, while debt/equity is not included in the ROE model. Additionally ROS and ROE models do not include DeltaGDP ${ }_{j}$ to account for economic fluctuations, but all models include the crisis indicator. Models employing ROA and ROE as a dependent variable produced a significant (and negative) relationship with CSP maturity.

Overall, regression results for the models reveal several relationships. First, while the ROS model does not show a statistically significant $\beta$ coefficient for CSP maturity, both the ROA and ROE models confirm a negative relationship between CSP maturity and CFP. This result supports prior correlation analysis, and affirms the traditionalist view that argues CSP leads to limited benefits for the company, with significant additional costs, rejecting $\mathrm{H} 3$.

Second, the negative relationship between D/E and ROS and ROA follows results by Callan and Thomas (2009); this may be explained by the notion that highly leveraged companies require greater operating income in order to keep the same level of financial results. Capital expenditures are insignificant in all regressions; there may be a lag greater than one year between the time a firm invests and the resulting financial rewards. In all models, the $\beta$ coefficient on total assets is negative, but positive on the number of employees. These results do not follow those of other empirical research. For example Fauzi (2009a) reported a positive relationship between total assets and ROA and ROE; Callan and Thomas (2009) also reported a positive relationship between total assets and ROA, ROE and ROS. The negative relationship between total assets and CFP may be due to the economic crisis.

All models produce a negative beta coefficient for the crisis dummy variable; in other words, financial performance for all firms declined during 2008, as expected. The coefficient on the industry variable was positive for ROS and ROE, indicating a positive effect for banks, relative to insurance companies during the period sampled.

The generalization of the results presented above is limited: the models' residuals do not follow a normal distribution and are heteroscedastic. Overall, we conclude there is not enough evidence to accept H3; that is, we cannot conclude CSP maturity has a significantly positive influence on CFP.

\subsection{CSP is Determined by CFP}

Considering slack resource theory alongside CSP maturity, one could argue companies that are doing better financially can be involved more deeply into CSP. Similar to H3, this hypothesis measures CFP is by one of three financial ratios, and control variables remain the same.

\section{H4: CFP is a determinant of CSP maturity}

We find very strong adjusted $\mathrm{R}^{2}$ results, significantly better than in case of regressions with CFP as a dependent variable (H3). Model information criterion is also better for H4 than for H3: AIC, BIC and HQC ranges are much lower. Finally, the residuals of such model are distributed normally and generally follow a random pattern. Overall, as both regression models (H3 and H4) utilize identical data, one tends to conclude modeling CSP maturity as the dependent variable better suits the data, giving additional support to reject H3. Results from the final model are presented in Table 6 (Note 7). 
Table 6. Weighted least squares estimated model with CSP maturity as the dependent variable

\begin{tabular}{ll}
\hline & CSP Maturity \\
\hline const & $0.6059^{* *}$ \\
D/E & \\
Emp & $-4.884 \mathrm{e}-07^{* *}$ \\
TA & $4.013 \mathrm{e}-010^{* *}$ \\
Capex & $-4.256 \mathrm{e}-08^{* *}$ \\
DeltaGDP ${ }_{-} 1$ & $-0.06174^{* *}$ \\
Industry & $-0.1358^{* *}$ \\
CFP_1 & \\
N & 172 \\
Adj. $R^{2}$ & 0.9113 \\
LnL & -236.5 \\
AIC & 485.1 \\
BIC & 504.0 \\
HQC & 492.7 \\
\hline
\end{tabular}

While initial regressions holding CSP as dependent variable were performed to include all financial performance ratios (ROA, ROE, ROS), none are included in the final model (the p-values of all $\beta$ coefficients are not statistically different from zero) suggesting CSP maturity is determined by control variables but not by company financial results. Similar results showing no relationship between CSP and CFP were obtained by Chih et al. (2009), Fauzi (2009b) and Nelling \& Webb (2009). These results contrast with the slack resource theory which argues better financial performance leads to slack resources allowing companies to more fully engage in CSP activities. Overall, $\mathrm{H} 4$ is rejected.

Other results are mixed. We find total assets positive related with CSP maturity, yet the number of employees is negatively related to CSP maturity. As both proxy firm size, the results are contradicting, and difficult to interpret, although they could be related to the economic recession. The industry dummy variable is negative suggesting banks are less prone to engaging in strategic CSP activities than are insurance companies.

Another interesting observation in Table 6 relates to capital expenditures. Although this variable was not included in any of the models tested under H3, it seems to be significant in the model with CSP maturity as the dependent variable. Capital expenditures are analyzed as a negative figure, as recorded in the cash flow statement. The negative relationship implies the greater the amount spent for capital expenditures, the more likely the company is to be involved with strategic CSP. Such a relationship could be explained by the notion that capital expenditures include expenses which are used to acquire intangible assets and capital expenditures may include costs the company incurred due to advertising or CSP. The negative relationship between CSP maturity and capital expenditures may suggest such expenditures are one of the means to measure financial resources allocated for CSP.

\section{Limitations}

The main limitation of this study relates to the generalization of the results as our sample contained only bank and insurance companies, and included a time period subject to a worldwide economic downturn. A theory explaining the impact of the economic crisis on CSP investment is also missing; therefore it is complicated to compare the results of this study and comment on their repetitiveness or wider applicability.

Second, CSP maturity is measured by using external publicly available information such as company annual reports. The limitation of this data lies in the fact that CSP maturity is not supported by comments from companies' executives. It would be beneficial to support CSP maturity measurement by an interview or questionnaire filled in by company executives to validate the assumptions, and serve as an additional source of measurement. Additionally in the current study CSP maturity addresses only the quality aspect of the CSP maturity; incorporating the quantity aspect would have made CSP maturity data more detailed and allowed for a deeper analysis.

Finally, CFP could also be measured as share price fluctuations in the market. Additionally more industry specific variables, such as HHI market concentration index, could be employed. These variables were not included due to unavailability of the data. 


\section{Implications for Future Research}

Future researchers should seek to continue refining CSP maturity operationalization. Employing a questionnaire or an interview with company executives would certainly strengthen evidence that the company is really engaged in strategic CSP. Further studies should also try to incorporate the quantity aspect of CSP maturity; we use the CSP maturity indicator to assess only the quality of company engagement.

Second, the literature is quite disbursed when it comes to CFP measurement, with no clear consensus. Orlitzky et al. (2003) note accounting measures capture past performance, whereas market measures evaluate future performance, but are considered noisier since they are affected by external factors. The choice of CFP measurement is a fruitful avenue for future research. Studies that utilizes multiple measures and compare the robustness of the results would provide useful information for researchers.

Third, the time lagging phenomenon needs more detailed analysis. We utilize a one year lag between CFP maturity and CSP, which produced a stronger relationship than no lag and a two year lag for our sample. Additional work with varying time periods may solidify whether or not a long-run impact exists in the CSP maturity-CFP relationship.

Fourth are sample considerations. Many studies use Fortune ratings, S\&P 500 index, or listing in some mutual fund or stock exchange for sample construction, which naturally skews the sample toward large firms. From a geographical perspective, the majority of prevailing studies are performed on U.S. companies, which may limit the generalization of results (Callan \& Thomas, 2009). While not an issue methodologically, consideration of a broader scope of firms may uncover cultural biases in the CSP maturity-CFP relationship, not previously found. For studies performed in Europe, it would be beneficial to account for geographical or economic maturity differences.

The last implication for future studies relates to industry specifics. Researchers should consider how industry may influence modeling, analysis, and variable selection. The specific characteristics of an industry may very well influence the selection of appropriate CSP and CFP measurements. Perhaps the reason universally accepted CSP andCFP measures have yet to be attained is because they they are industry-dependent.

\section{Conclusion}

We utilize panel data containing information on 86 large European banks and insurance companies measured. We operationalize CFP using ROA, ROE, and ROS. CSP maturity is measured as years of continuous involvement in strategic CSP. Correlation analysis was utilized to verify the CSP maturity and CFP relationship direction. Mean differences of ROA, ROE and ROS were compared between companies engaged in strategic versus ad-hoc CSP. Weighted least squares regression tested two models of the CSP maturity and CFP relationship.

We find CSP maturity and CFP are statistically negatively correlated. Independent sample t-test showed statistically significant different means of ROA and ROS for companies engaged in strategic and ad-hoc CSP. Ad-hoc companies were associated with better ROA and ROS. No significant difference was present for ROE. Regression analysis did not show a relationship between CSP maturity and CFP. This indicates that neither CSP maturity has an impact on CFP nor can CFP be used to explain CSP maturity. The results of this study are limited in their generalization, because the data included a global economic recession.

The question of why companies engage in strategic CSP is still open. To answer, one must determine the benefits CSP brings, if not directly expressed in better financial results. Godfrey, Merrill, \& Hansen (2009) argue that by engaging in CSP, companies gain sort of "insurance" benefit in case of a negative event. Luo \& Bhattacharya (2009) argue CSP may serve as a control tool for firm-idiosyncratic risk of market returns. This supports the notion that CSP benefits may be attributed not with financial ratios, but with some other ratios that define the quality of company operations. The investigation of these benefits could serve as an implication for future studies.

\section{References}

Bragdon, J. H., \& Marlin, J. A. T. (1972). Is pollution profitable? Risk Management, 19(4), 9-18.

Brammer, S., \& Millington, A. (2008). Does it pay to be different? An analysis of the relationship between corporate social and financial performance. Strategic Management Journal, 29, 1325-1343. http://dx.doi.org/10.1002/smj.714 
Callan, S. J., \& Thomas, J. M. (2009). Corporate financial performance and corporate social performance: An update and reinvestigation. Corporate Social Responsibility and Environmental Management, 16, 61-78. http://dx.doi.org/10.1002/csr.182

Chih, H. L., Chih, H. H., \& Chen, T. Y. (2009). On the determinants of corporate social responsibility: International evidence on the financial industry. Journal of Business Ethics, 93, 115-135. http://dx.doi.org/10.1007/s10551-009-0186-x

Dahlsrud, A. (2006). How corporate social responsibility is defined: An analysis of 37 definitions. Corporate Social Responsibility and Environmental Management, 15(1), 1-13. http://dx.doi.org/10.1002/csr.132

Doh, J. P., \& Guay, T. R. (2006). Corporate Social Responsibility, Public Policy, and NGO Activism in Europe and the United States: An Institutional-Stakeholder Perspective. Journal of Management Studies, 43(1), 47-73. http://dx.doi.org/10.1111/j.1467-6486.2006.00582.x

Fauzi, H. (2009a). Corporate social and financial performance: Empirical evidence from American companies. Globsyn Management Journal, 3(1), 25-34.

Fauzi, H. (2009b). The determinants of the relationship of corporate social performance and financial performance: Conceptual framework. Issues in Social and Environmental Accounting, 2, 233-259.

Freeman, R. E. (1984). Strategic management: A stakeholder approach. Boston, MA: Pitman.

Friedman, M. (1970, September 13). The social responsibility of business is to increase its profits. New York Times Magazine, 122-126.

Garcia-Castro, R., Arino, M. A., \& Canela, M. A. (2009). Does social performance really lead to financial performance? Journal of Business Ethics, 92, 107-126. http://dx.doi.org/10.1007/s10551-009-0143-8

Goddard, J., Molyneux, P., \& Wilson, J. O. S. (2004). Dynamics of growth and profitability in Banking. Journal of Money, Credit, and Banking, 36, 1070-1090. http://dx.doi.org/10.1353/mcb.2005.0015

Godfrey, P. C., Merrill, C. B., \& Hansen, J. M. (2009). The relationship between corporate social responsibility and shareholder value: An empirical test of the risk management hypothesis. Strategic Management Journal, 30, 425-445. http://dx.doi.org/10.1002/smj. 750

Griffin, J. J., \& Mahon, J. F. (1997). The corporate social performance and corporate financial performance debate: Twenty-five years of incomparable research. Business and Society, 36(1), 5-31. http://dx.doi.org/10.1177/000765039703600102

Hart, S. L., \& Ahuja, G. (1996). Does it pay to be green? An empirical examination of the relationship between emission reduction and firm performance. Business Strategy and the Environment, 5(1), 30-37. http://dx.doi.org/10.1002/(SICI)1099-0836(199603)5:1<30::AID-BSE38>3.0.CO;2-Q

Hillman, A. J., \& Keim, G. D. (2001). Shareholder value, stakeholder management, and social issues: What's the $\begin{array}{lllll}\text { bottom line? Strategic } & \text { Management }\end{array}$ http://dx.doi.org/10.1002/1097-0266(200101)22:2<125::AID-SMJ150>3.0.CO;2-H

Husted, B. W., \& Salazar, J. J. (2006). Taking Friedman Seriously: Maximizing profits and social performance. Journal of Management Studies, 43(1), 75-91. http://dx.doi.org/10.1111/j.1467-6486.2006.00583.x

Kaplan, R. S., \& Norton, D. P. (2007). Using the balanced scorecard as a strategic management system. Harvard Business Review, 85, 150-160.

Kaplan, R. S. \& Norton, D. P. (2000). The strategy-focused organization. Harvard Business School Press, Boston, MA.

Laan, G. V., Ees, H. V., \& Witteloostuijn, A. V. (2007). Corporate social and financial performance: An extended stakeholder theory and empirical test with accounting measures. Journal of Business Ethics, 79, 299-310. http://dx.doi.org/10.1007/s10551-007-9398-0

Lankoski, L. (2008). Corporate responsibility activities and economic performance: A theory of why and how they are connected. Business Strategy and the Environment, 17, 536-547. http://dx.doi.org/10.1002/bse.582

Lopez, M. V., Garcia, A., \& Rodriguez, L. (2007). Sustainable development and corporate performance: A study based on the Dow Jones Sustainability Index. Journal of Business Ethics, 75, 285-300. http://dx.doi.org/10.1007/s10551-006-9253-8 
Luo, X., \& Bhattacharya, C. B. (2009). The debate over doing good: Corporate social performance, strategic marketing levers, and firm idiosyncratic risk. Journal of Marketing, 73, 198-213. http://dx.doi.org/10.1509/jmkg.73.6.198

Makni, R., Francoeur, C., \& Bellavance, F. O. (2008). Causality between corporate social performance and financial performance: Evidence from Canadian firms. Journal of Business Ethics, 89, 409-422. http://dx.doi.org/10.1007/s10551-008-0007-7

Margolis, J. D., Elfenbein, H. A., \& Walsh, J. P. (2007). Does it pay to be good? A meta-analysis and redirection of research on the relationship between corporate social and financial performance. Working paper, Ross School of Business, University of Michigan.

Mill, G. A. (2006). The financial performance of socially responsible investment over time and a possible link with corporate social responsibility. Journal of Business Ethics, 63(2), 131-148. http://dx.doi.org/10.1007/s10551-005-2410-7

Nelling, E., \& Webb, E. (2009). Corporate social responsibility and financial performance: The "virtuous circle" revisited. Review of Quantitative Finance and Accounting, 32, 197-209. http://dx.doi.org/10.1007/s11156-008-0090-y

Orlitzky, M., Schmidt, F. L., \& Rynes, S. L. (2003). Corporate social and financial performance: A meta-analysis. Organization Studies, 3(24), 403-441. http://dx.doi.org/10.1177/0170840603024003910

Peters, R., \& Mullen, M. R. (2009). Some evidence of the cumulative effects of corporate social responsibility on financial performance. Journal of Global Business Issues, 3(1), 1-15.

Rettab, B., Brik, A. B., \& Mellahi, K. (2008). A study of management perceptions of the impact of corporate social responsibility on organizational performance in emerging economies: The case of Dubai. Journal of Business Ethics, 89, 371-390. http://dx.doi.org/10.1007/s10551-008-0005-9

Rowley, T., \& Berman, S. (2000). A brand new brand of corporate social performance. Business and Society, 39, 397-418. http://dx.doi.org/10.1177/000765030003900404

Sadler, P. (2003). Strategic Management (2nd ed.). London: Kogan Page Limited.

Simpson, W. G., \& Kohers, T. (2002). The link between corporate social and financial performance: Evidence from the banking industry. Journal of Business Ethics, 35, 97-109. http://dx.doi.org/10.1023/A:1013082525900

Uwuigbe, U., \& Egbide, B. C. (2012). Corporate social responsibility disclosures in Nigeria: A study of listed financial and non-financial firms. Journal of Management and Sustainability, 2(1), 160-169. http://dx.doi.org/10.5539/jms.v2n1p160

Waddock, S. A., \& Graves, S. B. (1997). The corporate social performance - financial performance link. $\begin{array}{llll}\text { Strategic Management } & \text { Journal, } & \text { 303-319. }\end{array}$ http://dx.doi.org/10.1002/(SICI)1097-0266(199704)18:4<303::AID-SMJ869>3.0.CO;2-G

Wells, D. L. (1996). Strategic Management for Senior Leaders: A Handbook for Implementation (TQLO Pub. No. 96-03). Washington, DC: Total Quality leadership Office, Department of the Navy.

$\mathrm{Wu}$, M. L. (2006). Corporate social performance, corporate financial performance, and firm size: A meta-analysis. Journal of American Academy of Business, 8(1), 163-171.

\section{Notes}

Note 1. www.danone.com/images/pdf/dan_ratechdevdurable_en.pdf

Note 2.

www.kpmg.com/Global/en/IssuesAndInsights/ArticlesPublications/Documents/International-corporate-responsi bility-survey-2008.pdf

Note 3. Correlations were calculated for each year in the sample and then averaged.

Note 4. We use a one-year CSP-CFP lag. To examine the validity of this assumption, we perform the correlation analysis with no lag and a two-year lag. Correlation coefficients are weaker in the latter cases, supporting use of a one-year lag.

Note 5. Weighted least squares regression was chosen because the error terms did not exhibit constant variation and standard OLS may be too robust. 
Note 6. We examine the scatter plots between ROA, ROE and ROS with CSP_perc_1 (lagged one year) to examine the core properties of the data. First, the data exhibits heteroscedasticity; the ratios are not distributed equally between CSP_perc_1 values (also seen in the descriptive data analysis). Second the data follow a generally visible linear trend, although not strongly inclined. Finally, all three ratios contain outlier points. Taken together, these results suggest the data does not follow a normal distribution. Square, exponential and squared root transformations were estimated to improve data normality however this did not provide any positive results. Overall, the data's characteristics have a weakening impact on our regression results. We also test for multicolinearity. The strongest relationship is between the number of employees and total assets, consistent with the correlation results, but the relationship does not exceed expected normal values.

Note 7. As with $\mathrm{H} 3$, regression models were initially constructed with all control variables. AIC, AICC, BIC and log likelihood were used in subsequent model iterations to distinguish which model best suits the data. Variables having the highest p-value were sequentially removed. Tests for multicolinearity produced VIF values ranging from 2.54 to 1.08 , which indicate the model's variables are not significantly dependent on one another. We find the residuals follow a normal distribution, are homoskedastic and exhibit a random distribution pattern, supporting the model's suitability.

Appendix 1. Weighted least squares with ROA as the dependent variable

\begin{tabular}{llllll}
\hline & ROA1 & ROA2 & ROA3 & ROA4 & ROA5 \\
\hline Constant & $0.008378^{* *}$ & $0.008378^{* *}$ & $0.007730^{* *}$ & $0.009728^{* *}$ & $0.008190^{* *}$ \\
& $(0.0008032)$ & $(0.0007987)$ & $(0.0005624)$ & $(0.0007898)$ & $(0.0006390)$ \\
D/E_1 & $-0.0001394^{* *}$ & $-0.0001394^{* *}$ & $-0.0001963^{* *}$ & $-0.0001935^{* *}$ & $-0.0001221^{* *}$ \\
& $-5.82 \mathrm{e}-02$ & $-5.62 \mathrm{e}-02$ & $-5.00 \mathrm{e}-02$ & $-5.00 \mathrm{e}-02$ & $-4.85 \mathrm{e}-02$ \\
Emp_1 & $3.498 \mathrm{e}-08^{* *}$ & $3.505 \mathrm{e}-08^{* *}$ & $2.988 \mathrm{e}-08^{* *}$ & $3.146 \mathrm{e}-08^{* *}$ & $3.551 \mathrm{e}-08^{* *}$ \\
& $-6.97 \mathrm{e}-06$ & $-6.80 \mathrm{e}-06$ & $-5.76 \mathrm{e}-06$ & $-5.36 \mathrm{e}-06$ & $-4.61 \mathrm{e}-06$ \\
DeltaGDP $i$ & $0.001744^{* *}$ & $0.001744^{* *}$ & $0.001786^{* *}$ & $0.001456^{* *}$ & $0.001584^{* *}$ \\
& $(0.0001408)$ & $(0.0001404)$ & $(0.0001406)$ & $(0.0002015)$ & $(0.0001703)$ \\
CSP_perc_1 & -0.001078 & -0.001077 & $-0.001301^{*}$ & $-0.001809^{* *}$ & $-0.001753^{* *}$ \\
& $(0.0006681)$ & $(0.0006652)$ & $(0.0006915)$ & $(0.0006874)$ & $(0.0005804)$ \\
TA_1 & $-9.416 \mathrm{e}-012^{* *}$ & $-9.420 \mathrm{e}-012^{* *}$ & $-8.146 \mathrm{e}-012^{* *}$ & $-8.650 \mathrm{e}-012^{* *}$ & $-8.531 \mathrm{e}-012^{* *}$ \\
& $-1.11 \mathrm{e}-09$ & $-1.06 \mathrm{e}-09$ & $-9.78 \mathrm{e}-10$ & $-9.44 \mathrm{e}-10$ & $-9.57 \mathrm{e}-10$ \\
Capex_1 & $-4.09 \mathrm{e}-09$ & & & & \\
& $-2.30 \mathrm{e}-07$ & & & & \\
Industry & -0.0008506 & -0.0008492 & & & \\
Crisis & $(0.0006192)$ & $(0.0006027)$ & & $-0.002026^{* *}$ & $-0.001280^{* *}$ \\
& & & & $(0.0005527)$ & $(0.0004601)$ \\
n & & & 258 & 258 \\
Adj. R ${ }^{2}$ & 258 & 258 & 0.6677 & 0.7333 & 0.7249 \\
lnL & 0.6454 & 0.6468 & & -344 & -348 \\
& -345 & -345 & & 702 & 710 \\
AIC & 706 & 704 & 715 & 727 & 735 \\
BIC & 734 & 729 & & 712 & 720 \\
HQC & 717 & 714 & & & \\
\hline
\end{tabular}


Appendix 2. Weighted least squares with ROE as the dependent variable

\begin{tabular}{llllll}
\hline & ROE1 & ROE2 & ROE3 & ROE4 & ROE5 \\
\hline Constant & $0.09850^{* *}$ & $0.1012^{* *}$ & $0.1013^{* *}$ & $0.1637^{* *}$ & $0.1728^{* *}$ \\
& $(0.007749)$ & $(0.008059)$ & $(0.008062)$ & $(0.008879)$ & $(0.005475)$ \\
D/E_1 & -0.0007432 & & & \\
& $(0.0008727)$ & & & & \\
Emp_1 & $3.319 \mathrm{e}-07^{* *}$ & $3.896 \mathrm{e}-07^{* *}$ & $3.704 \mathrm{e}-07^{* *}$ & $4.094 \mathrm{e}-07^{* *}$ & $4.269 \mathrm{e}-07^{* *}$ \\
& $-8.99 \mathrm{e}-05$ & $-9.31 \mathrm{e}-05$ & $-8.62 \mathrm{e}-05$ & $-8.66 \mathrm{e}-05$ & $-8.58 \mathrm{e}-05$ \\
DeltaGDP ${ }_{\mathrm{j}}$ & $0.01996^{* *}$ & $0.01952^{* *}$ & $0.01952^{* *}$ & 0.003108 & \\
& $(0.001442)$ & $(0.001510)$ & $(0.001509)$ & $(0.002360)$ & \\
CSP_perc_1 & $-0.01759^{* *}$ & $-0.01824^{* *}$ & $-0.01879^{* *}$ & $-0.03561^{* *}$ & $-0.03664^{* *}$ \\
& $(0.007274)$ & $(0.007602)$ & $(0.007508)$ & $(0.007864)$ & $(0.007916)$ \\
TA_1 & $-6.663 \mathrm{e}-011^{* *}$ & $-7.885 \mathrm{e}-011^{* *}$ & $-7.840 \mathrm{e}-011^{* *}$ & $-8.630 \mathrm{e}-011^{* *}$ & $-9.103 \mathrm{e}-011^{* *}$ \\
& $-1.54 \mathrm{e}-08$ & $-1.53 \mathrm{e}-08$ & $-1.53 \mathrm{e}-08$ & $-1.69 \mathrm{e}-08$ & $-1.64 \mathrm{e}-08$ \\
Capex_1 & $1.97 \mathrm{e}-06$ & $1.71 \mathrm{e}-06$ & & & \\
& $-1.90 \mathrm{e}-06$ & $-2.12 \mathrm{e}-06$ & & & \\
Industry & $0.01274^{* *}$ & $0.009238^{*}$ & $0.009146^{*}$ & $0.01687^{* *}$ & $0.01906^{* *}$ \\
& $(0.004578)$ & $(0.004897)$ & $(0.004922)$ & $(0.005825)$ & $(0.005690)$ \\
Crisis & & & & $-0.07470^{* *}$ & $-0.08201^{* *}$ \\
& & & & $(0.008308)$ & $(0.006063)$ \\
N & 258 & 258 & 258 & 258 & 258 \\
Adj. ${ }^{2}$ & 0.6885 & 0.6431 & 0.6423 & 0.5564 & 0.5602 \\
lnL & -361 & -361 & -360 & -352 & -353 \\
& & & & & 718 \\
AIC & 737 & 735 & 733 & 719 & 726 \\
BIC & 766 & 760 & 754 & 744 & 739 \\
HQC & 749 & 745 & & & \\
\hline
\end{tabular}

Appendix 3. Weighted least squares with ROS as the dependent variable

\begin{tabular}{llllllll}
\hline & ROS1 & ROS2 & ROS3 & ROS4 & ROS5 & ROS6 & ROS7 \\
\hline Constant & $0.05361^{* *}$ & $0.05417^{* *}$ & $0.05866^{* *}$ & $0.1181^{* *}$ & $0.1167^{* *}$ & $0.1273^{* *}$ & $0.1242^{* *}$ \\
& $(0.005951)$ & $(0.005839)$ & $(0.005084)$ & $(0.009725)$ & $(0.009708)$ & $(0.005596)$ & $(0.004924)$ \\
D/E_1 & $-0.00220^{* *}$ & $-0.00208^{* *}$ & $-0.00210^{* *}$ & $-0.00218^{* *}$ & $-0.00194^{* *}$ & $-0.00178^{* *}$ & $-0.00187^{* *}$ \\
& $(0.000789)$ & $(0.0007765)$ & $(0.0008030)$ & $(0.0007453)$ & $(0.0007788)$ & $(0.0008024)$ & $(0.0007875)$ \\
Emp_1 & $4.875 \mathrm{e}-07^{* *}$ & $5.066 \mathrm{e}-07^{* *}$ & $4.993 \mathrm{e}-07^{* *}$ & $4.542 \mathrm{e}-07^{* *}$ & $4.810 \mathrm{e}-07^{* *}$ & $4.905 \mathrm{e}-07^{* *}$ & $4.957 \mathrm{e}-07^{* *}$ \\
& $-9.76 \mathrm{e}-05$ & $-9.44 \mathrm{e}-05$ & $-9.46 \mathrm{e}-05$ & $-7.82 \mathrm{e}-05$ & $-7.76 \mathrm{e}-05$ & $-7.68 \mathrm{e}-05$ & $-7.64 \mathrm{e}-05$ \\
DeltaGDP & $0.01801^{* *}$ & $0.01778^{* *}$ & $0.01718^{* *}$ & 0.002323 & 0.002565 & & \\
& $(0.001521)$ & $(0.001518)$ & $(0.001459)$ & $(0.002295)$ & $(0.002277)$ & & \\
CSP_perc_1 & 0.009164 & 0.009931 & & -0.005614 & -0.003885 & -0.008419 & \\
& $(0.006495)$ & $(0.006419)$ & & $(0.008398)$ & $(0.008255)$ & $(0.007887)$ & \\
TA_1 & $-1.21 \mathrm{e}-01^{* *}$ & $-1.25 \mathrm{e}-01^{* *}$ & $-1.18 \mathrm{e}-01^{* *}$ & $-1.25 \mathrm{e}-01^{* *}$ & $-1.29 \mathrm{e}-01^{* *}$ & $-1.31 \mathrm{e}-01^{* *}$ & $-1.36 \mathrm{e}-01^{* *}$ \\
& $-1.30 \mathrm{e}-08$ & $-1.36 \mathrm{e}-08$ & $-1.34 \mathrm{e}-08$ & $-1.44 \mathrm{e}-08$ & $-1.57 \mathrm{e}-08$ & $-1.59 \mathrm{e}-08$ & $-1.52 \mathrm{e}-08$ \\
Capex_1 & $2.97 \mathrm{e}-07$ & & & $-9.26 \mathrm{e}-07$ & & & \\
& $-3.12 \mathrm{e}-06$ & & & $-3.16 \mathrm{e}-06$ & & & \\
Industry & $0.09566^{* *}$ & $0.09510^{* *}$ & $0.09445^{* *}$ & $0.09987 * *$ & $0.09912^{* *}$ & $0.09998^{* *}$ & $0.1015^{* *}$ \\
& $(0.005003)$ & $(0.004974)$ & $(0.005001)$ & $(0.006065)$ & $(0.006116)$ & $(0.006230)$ & $(0.006082)$ \\
Crisis & & & & $-0.07076^{* *}$ & $-0.06910^{* *}$ & $-0.07681^{* *}$ & $-0.07776^{* *}$ \\
& & & & $(0.007421)$ & $(0.007554)$ & $(0.005257)$ & $(0.005123)$ \\
N & 258 & 258 & 258 & 258 & 258 & 258 & 258 \\
Adj. ${ }^{2}$ & 0.7686 & 0.7590 & 0.7497 & 0.7252 & 0.7155 & 0.7310 & 0.7299 \\
lnL & -360 & -359 & -360 & -356 & -355 & -357 & -357 \\
& & & & & & 727 & 725 \\
AIC & 736 & 733 & 731 & 730 & 727 & 727 & 747 \\
BIC & 765 & 758 & 752 & 762 & 755 & 752 & 737 \\
HQC & 748 & 743 & 740 & 743 & 738 & 737 & \\
\hline
\end{tabular}

